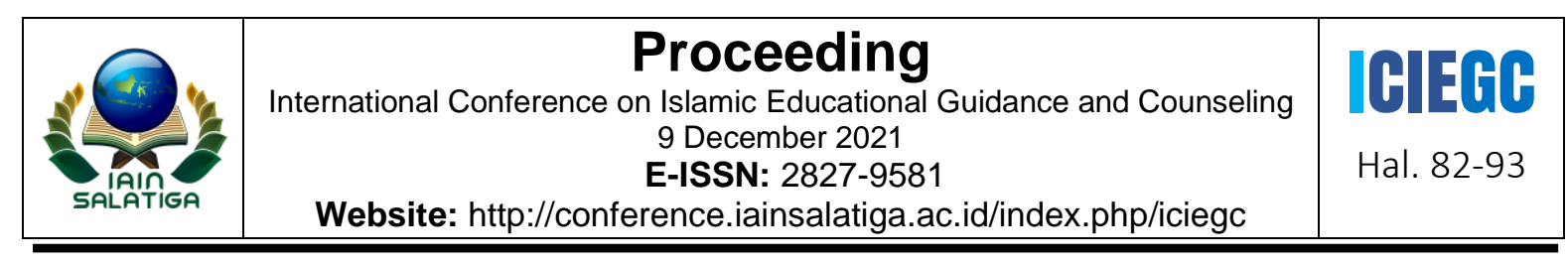

\title{
PENGARUH SUPERVISI BIMBINGAN KONSELING TERHADAP EFEKTIVITAS PELAKSANAAN PROGRAM BK DI SEKOLAH (STUDI KASUS DI 30 SMP PROVINSI BENGKULU TAHUN 2020)
}

\author{
Afrika Yunani ${ }^{1}$, Febriani Putri Utami ${ }^{2}$, Vera Yusnita $^{3}$, Aframa Yeni ${ }^{4}$, Beni Azwar $^{5}$ \\ 1,2,3,4 IAIN Curup
}

\begin{tabular}{l}
\hline \hline Informasi Artikel \\
\hline Penulis Korespondensi: \\
Afrika Yunani \\
Email: \\
afrikayunani@gmail.com
\end{tabular}

\begin{abstract}
This study aims to determine whether there is an effect of BK supervision on the effectiveness of the implementation of the BK program in schools. The method used is quantitative with quantitative descriptive research type, with a sample of 30 schools at the junior high school level in Bengkulu Provision. Data collection was carried out by distributing the BK program supervision questionnaire. The data from this study were obtained with the help of SPSS Statistics Version 17.0. Then the analysis used in this research is Simple Linear Regression Analysis. The results of the study found that BK supervision carried out at the junior high school education level in Bengkulu province was in the poor category with a percentage of $40 \%$ and the BK program carried out at the junior high school education level in Bengkulu province was in the Good category with a percentage of $43,3 \%$. Then the significance value obtained from the simple linear regression test is $0.101 \geq 005$,. Then the hypothesis $\mathrm{HO}$ is accepted and $\mathrm{Ha}$ is rejected, which means that there is no positive influence of BK supervision on the effectiveness of the implementation of the BK program in schools.
\end{abstract}

\begin{abstract}
Keyword: Supervision; guidance and counseling program ABSTRAK

Penelitian ini bertujuan untuk mengetahui adakah pengaruh supervisi BK terhadap efektivitas pelaksanaan program BK di sekolah. Metode yang digunakan adalah kuantitatif dengan jenis penelitian deskriptif kuantitatif, dengan sampel 30 sekolah pada tingkat pendidikan SMP di Provisi Bengkulu. Pengumpulan data dilakukan melalui penyebaran angket supervisi program BK. Data hasil penelitian ini diperoleh dengan bantuan SPSS Statistics Version 17.0. Kemudian analisis yang digunakan dalam penelitian ini yaitu Analisis Regresi Linier Sederhana. Hasil penelitian di temukan bahwa supervisi BK yang dilakukan pada tingkat pendidikan SMP yang ada di dalam provinsi Bengkulu dalam kategori kurang Baik dengan persentase yaitu $40 \%$ dan program BK yang dilakukan pada tingkat pendidikan SMP yang ada di dalam provinsi Bengkulu dalam kategori Baik dengan persentase $43,3 \%$. Kemudian di peroleh nilai signifikansi dari uji regresi linier sederhana yaitu $0,101 \geq 0,05$. Maka hipotesis $\mathrm{H} 0$ diterima dan Ha ditolak, yang artinya menyatakan tidak terdapat pengaruh yang positif supervisi BK terhadap efektifitas pelaksanaan program BK di sekolah.
\end{abstract}

Kata kunci: Supervisi; program bimbingan dan konseling di sekolah 


\section{PENDAHULUAN}

Pendidikan adalah usaha sadar yang bertujuan untuk mendewasakan individu dalam mencapai tugas-tugas perkembangannya. Hadisumarto dalam Azwar, dkk. (2020) menegaskan bahwa pendidikan yang dapat memfasilitasi berbagai perubahan yaitu disebut pendidikan yang merata, bermutu, dan relevan dengan kebutuhan masyarakatnya.

Pendidikan berperan penting dalam mengoptimalkan potensi diri siswa melalui proses pembelajaran sehingga menghasilkan individu yang berkualitas. Keberhasilan dalam pembelajaran yang diikuti oleh peserta didik banyak faktor yang menyebabkan masalah dalam belajar yaitu lingkungan sekolah, terutama guru (Kusen, 2016).

Guru Bimbingan dan Konseling (BK) sebagai seorang konselor di sekolah masih mengalami berbagai kendala dan masalah yang beragam dari berbagai macam faktor sehingga tak banyak sekolah yang mampu melaksanakan layanan Bimbingan dan Konseling dengan baik. Sehingga masalah ini harus segera disikapi dan dituntaskan secara positif agar rasa percaya diri guru BK bertambah dan meningkat dalam menjalankan tugasnya, karena layanan Bimbingan dan Konseling semakin tumbuh dan berkembang sehingga guru BK penting untuk menyadari bahwa pertumbuhan dan perkembangan profesi ialah suatu keharusan untuk kinerja dan layanan yang berkualitas (Amelisa \& Suhono, 2018).

Bukan hanya masalah akademik, akan tetapi yang harus diperhatikan adalah masalah pengoptimalisasian potensi yang dimiliki oleh peserta didik. Hal ini akan berkenaan langsung dengan tugas dan tanggung jawab seorang guru BK untuk memberikan pelayanan layanan BK kepada peserta didik agar mereka tumbuh secara optimal dengan segala bakat, minat dan potensi yang mereka punyai. Banyaknya tugas dan tanggung jawab yang harus dipikul oleh seorang guru BK yang mana terkadang justru membuat guru BK lalai akan tugas utama mereka yaitu memberikan pelayanan bimbingan dan konseling kepada peserta didik karena terlalu fokus terhadap pemenuhan administratif yang harus mereka buat (Widyowati, 2016).

Kegiatan bimbingan dan konseling dapat mencapai hasil yang efektif bilamana dimulai dari adanya program yang disusun dengan baik. Program berisi tentang rencana kegiatan yang akan dilakukan dalam rangka pemberian layanan bimbingan dan konseling. Program bimbingan dan konseling merupakan bagian yang terpadu dari keseluruhan program pendidikan di sekolah, maka program bimbingan dan konseling seluruh kegiatannya diarahkan kepada pencapaian tujuan pendidikan di lembaga yang bersangkutan. Selain itu program bimbingan dan konseling diarahkan kepada upaya yang 
memfasilitasi peserta didik untuk mengenal dirinya dan menerima dirinya sendiri serta lingkungannya secara positif dan dinamis, penyusunan program bimbingan dan konseling merupakan perwujudan diri secara efektif dan produktif, sesuai dengan peranan yang diinginkan (Giyono, 2015).

Penyusunan dan rancangan program dalam bimbingan dan konseling sangat memiliki peranan yang sangat penting dalam keberhasilan pelaksanaan layanan bimbingan di sekolah. Penyusunan program bimbingan dan konseling disekolah hendaknya harus disusun berdasarkan permasalahan yang dihadapi oleh peserta didik serta kebutuhankebutuhan yang dihadapi, sehingga akhirnya peserta didik dapat mencapai tujuan pendidikan itu sendiri berupa kedewasaan dalam bertindak dan berperilaku secara wajar sesuai dengan perkembangan mereka (Fatchurahman, 2017).

Sunaryo Kartadinata, dkk. dalam penelitiannya menunjukkan bahwa program bimbingan dan konseling (BK) di sekolah akan berlangsung efektif dan efisien apabila didasarkan pada kebutuhan nyata dan kondisi objektif perkembangan peserta didik (Kurniawan, 2015). Menurut Born didalam Fatchurahman Bimbingan dan konseling (BK) komprehensif sebagai sebuah model penyelenggaraan program BK komprehensif di sekolah telah terbukti efektif. Gysbers, berdasarkan studi yang dilakukannya mengungkapkan bahwa program bimbingan dan konseling komprehensif memberikan konstribusi pada pencapaian prestasi akademik peserta didik, Selanjutnya didalam Handerson mengemukakan empat komponen yang membentuk program bimbingan dan konseling komprehensif, yang meliputi: (1) pelayanan dasar, (2) perencanaan individual, (3) layanan responsif, dan (4) dukungan sistem (Fatchurahman, 2017).

Pada saat melaksanakan tugas layanan bimbingan dan konseling, Konselor atau Guru Bimbingan dan Konseling (BK) dapat berkolaborasi dengan berbagai pihak-pihak yang ada dalam satuan pendidikan dan di luar satuan pendidikan. Pihak-pihak pada satuan pendidikan diantaranya yaitu: kepala sekolah, wakil kepala sekolah, wali kelas, guru mata pelajaran, dan staf administrasi sekolah. Sedangkan pihak di luar satuan pendidikan yaitu meliputi komite sekolah, orang tua, organisasi profesi bimbingan dan konseling, organisasi profesi lain yang relevan, dan pengawas (Permendikbud, 2014). Ini merupakan sesuatu yang sangat penting dalam pengembangan bimbingan dan konseling serta merupakan salah satu bentuk kerjasama antara konselor atau guru BK dengan pihak di dalam sekolah dan di luar sekolah. Pengawas atau supervisor diharapkan dapat memberikan arahan, masukan, dan koreksi terhadap pelaksanaan bimbingan dan konseling (BK) di sekolah (Suwidagdho, dkk., 2017). 
Kegiatan supervisi dalam bimbingan dan konseling (BK) diantaranya yaitu pembinaan dan pemantauan dalam pelaksanaan bimbingan dan konseling di sekolah, yang merupakan kegiatan langsung berupa interaksi antara pengawas dengan guru binaanya. Melaksanakan penilaian kinerja guru dalam merencanakan, melaksanakan dan menilai proses pembimbingan. Kegiatan supervisi ini dilakukan di sekolah binaan, sesuai dengan uraian kegiatan yang telah disusun (Suwidagdho, dkk., 2017).

Kontribusi supervisi bimbingan dan konseling di sekolah memegang peranan penting dalam suatu organisasi pendidikan karena kegiatan supervisi dapat meningkatkan kinerja guru termasuk didalamnya yaitu kinerja guru BK. Kegiatan supervisi memungkinkan para guru memperoleh pemahaman diri dan belajar memecahkan masalah sendiri yang dihadapi dalam pembelajaran dengan imajinatif, penuh inisiatif dan kreativitas, bukan konformitas. Hal ini menunjukkan bahwa esensi adanya supervisi yang dilakukan oleh kepala sekolah berfokus pada sebuah perilaku supervisor dalam membimbing, mengarahkan dan memberikan masukan, kemudian membantu para guru pembimbing untuk meningkatkan kinerjanya agar dapat mengangkat harapan belajar siswa ke arah yang lebih baik (Widyowati, 2016).

Menurut Afrijawidiya dalam Suhertian terdapat beberapa pendekatan supervisi yang dapat dilakukan oleh seorang pengawas diantaranya yaitu dengan menggunakan pendekatan direktif, non-direktif, dan kolaboratif. Hal tersebut dapat lebih memudahkan pengawas ketika mensupervisi bawahannya. Pengawas dapat memilih pendekatan yang sesuai dengan kondisi lembaga atau sekolah yang disupervisi, karena di setiap pendekatan dalam supervisi pendidikan memiliki karakteristik yang berbeda. Pemilihan pendekatan yang tepat tergantung pada masalah yang dihadapi dan tujuan yang hendak dicapai (Afrijawidiya, 2017).

Pentingya supervisi ini juga dapat dilihat dari hasil penelitian yang telah dilakukan oleh Siraj dalam Tri widyowati yang mengemukakan bahwa supervisi memliki peran penting dalam peningkatan kinerja guru, selanjutnya mengungkapkan pula pelaksanaan supervisi pendidikan yang dilakukan oleh kepala sekolah untuk meningkatkan kemampuan guru bimbingan konseling (konselor) yaitu peningkatan sumber daya guru yang bisa dilaksanakan dengan bantuan supervisor yang melaksanakan kegiatan supervisi terhadap guru bimbingan dan konseling.

\section{METODE}


Pendekatan dalam penelitian ini menggunakan metode kuantitatif dengan jenis penelitian kuantitatif deskriptif. Penelitian ini akan mengungkapkan tentang gejala peristiwa dan kajian apa adanya yang sebenarnya terjadi. Jenis penelitian yang bertujuan untuk mendiskripsikan secara sistematis, faktual, dan akurat megenai fakta-fakta dan sifat populasi tertentu atau mencoba menggambarkan fenomena secara detail apa adanya (Hartini \& Fadila, 2015). Populasi dalam penelitian ini yaitu SMP Negeri yang ada di Provinsi Bengkulu. Dari populasi diperoleh 32 sampel, teknik pengambilan sampel dalam penelitian ini menggunakan teknik Probability sampling yaitu sampel yang telah ditentukan sebelumnya.

Pengumpulan data dilakukan melalui penyebaran angket supervisi program BK yang telah diuji validitas dan reabilitasnya. Hasil uji coba kuesioner atau angket yang terukur valid dan reliabel dengan jumlah 24 dari 53 item. Metode skala yang digunakan adalah skala likert dengan tipe plihan, yang terdiri atas empat kategori jawaban yaitu Slalu (S), Sering (SR), Jarang (JR), dan Tidak Pernah (TP), pembuatan angket mengacu pada variabel x dan y yaitu Supervisi dan Program BK. Koefisien reliabilitas dari skala angket supervisi program BK adalah sebesar 0,833. Data hasil penelitian ini diperoleh dengan bantuan SPSS Statistics Version 17.0.

Sebelum dilakukan uji hipotesis maka di cari terlebih dahulu seberapa besar persentase supervisi terhadap program BK yaitu dengan menggunakan rumus sebagai berikut (Sudjiono, 2015):

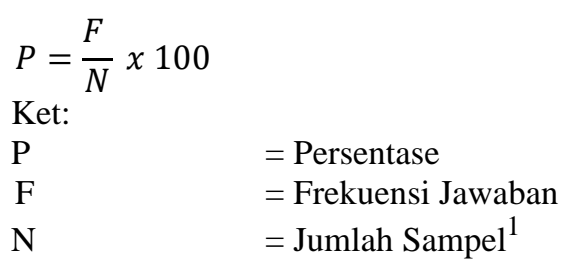

Selanjutnya dilakukan pengkategorisasian berdasarkan mean standar dan standar deviasi (SD), lihat tabel 1 (Sudjiono, 2015).

Kemudian analisis yang digunakan untuk melihat pengaruh supervisi terhadap progra BK dalam penelitian ini yaitu Analisis Regresi Linier Sederhana. Regresi Linier Sederhana adalah metode statistik yang berfungsi untuk menguji sejauh mana hubungan sebab akibat antara variabel faktor peneyebab x terhadap variabel akibatnya y. Program yang dipakai untuk analisis ini yaitu program SPSS Statistics 17.0.

\section{Tabel 1}




\section{Kategori Supervisi BK \\ Terhadap Efektivitas Pelaksanaan Program BK di Sekolah}

\begin{tabular}{lll}
\hline No & Rentang Norma & Kategori \\
\hline 1 & $\geq \mathrm{M}+1$ SD & Sangat Baik \\
\hline 2 & $\mathrm{M} \mathrm{X}<\mathrm{M}+1 \mathrm{SD}$ & Baik \\
\hline 3 & $\mathrm{M}-1 \mathrm{SD}$ X $<\mathrm{M}$ & Kurang Baik \\
\hline 4 & $\leq \mathrm{M}-1 \mathrm{SD}$ & Tidak Baik \\
\hline Ket: & & \\
$\mathrm{X}$ & $=$ Skor yang diperoleh & \\
SD & $=$ Standar Deviasi & \\
$\mathrm{M}$ & $=$ Mean & \\
\hline
\end{tabular}

Tabel 2

Kategori Supervisi BK di Sekolah (X)

\begin{tabular}{lllll}
\hline No & Rentang Skor & F & $\boldsymbol{\%}$ & Kategori \\
\hline 1 & $\geq 34$ & 8 & 26,6 & Sangat Baik \\
\hline 2 & $27-33$ & 7 & 23,3 & Baik \\
\hline 3 & $19-36$ & 12 & 40 & Kurang Baik \\
\hline 4 & $\leq 18$ & 3 & 10 & Tidak Baik \\
\hline Jumlah & 30 & 100 & \\
\hline
\end{tabular}

\section{HASIL DAN BAHASAN}

\section{Supervisi Bimbingan Konseling pada tingkat pendidikan (30 SMP yang ada di Provinsi Bengkulu)}

Hasil analisis data mengemukakan bahwa supervisi yang dilakukan pada tingkat pendidikan SMP yang ada di provisi Bengkulu termasuk dalam kategori kurang baik dalam pelaksaannya. Berdasarkan Hasil perhitungan pada tabel 2 dapat diketahui bahwa sebannyak 8 sekolah dengan persentase 26,6\% dalam kategori sangat baik, 7 sekolah dengan persentase 23,3\% dengan kategori baik, 12 sekolah dengan persentase 40\% dalam kategori kurang baik dan 3 sekolah dengan persentase 10\% kategori tidak baik. Sehingga dapat dikatakan bahwa supervisi BK yang dilakukan pada tingkat pendidikan SMP yang ada di dalam provinsi Bengkulu dalam kategori kurang Baik, terlihat pada grafik 1.

Dari hasil distribusi frekuensi responden secara keseluruhan pendekatan supervisi kolaboratif berada pada 53,3\% menjawab sering digunakan oleh supervisor ketika melakukan supervisi, 34\% pada pedekatan non direktif dan 24,4\% pendekatan kolabortif. Dari berbagai idikator pendekatan supervisi di dalam angket atau kuesioner yang telah di isi responden, diketahui bahwa pendekatan direktif yang lebih banyak digunakan oleh supervisor dalam mensupervisi BK di sekolah dengan persetase 53,3\%. 


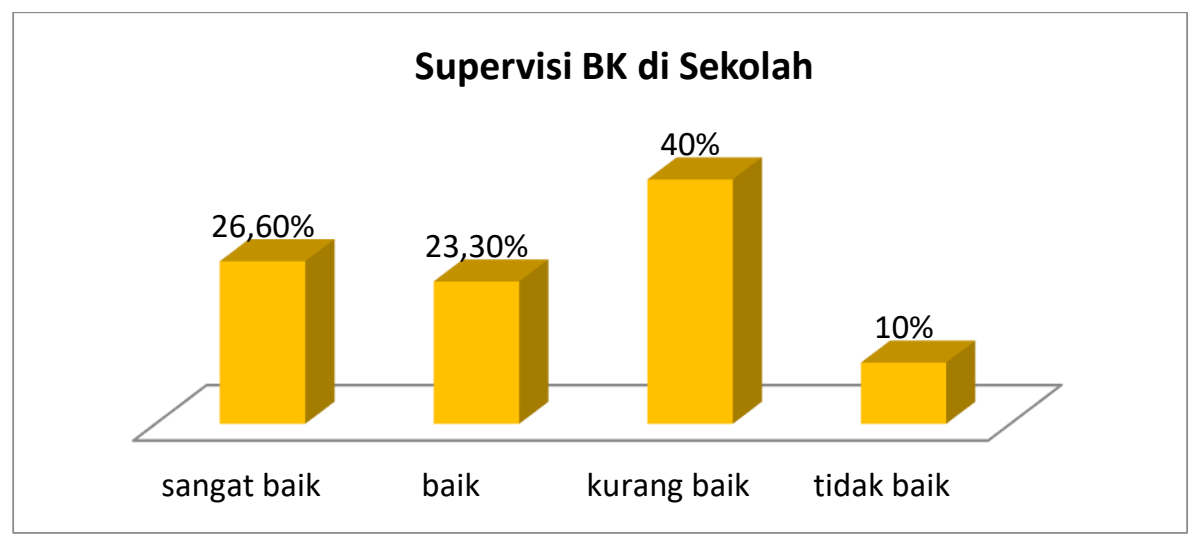

Grafik 1. Supervisi BK di Sekolah

Sehingga dilihat dari hasil yang diperoleh bahwa supervisi yang dilakukan di sekolah dalam satuan pendidikan SMP pada provinsi Bengkulu Kurang baik, hal ini berhubungan dengan pendekatan yang dipakai oleh supervisor yaitu pendekatan direktif. Karena pendekatan direktif Supervisor memberikan arahan langsung". Dalam hal ini tentu peran supervisor lebih dominan. Supervisor juga dapat menggunakan penguatan dan pemberian hukuman. Pendekatan ini didasarkan pada pemahaman psikologi behaviorisme, dengan adanya stimulus terhadap respon atau rangsangan. Namun para ahli berpendapat bahwa seperti yang dikutip Mufidah, bahwa "pola ini dianggap kurang efektif dan mungkin kurang manusiawi, karena guru yang disupervisi tidak diberi kesempatan untuk mengembangkan kemampuan dan kreatifitas mereka (Mufidah, 2008).

Supervisi dengan menggunakan pendekatan ini, menuntut supervisor yang aktif. Supervisor jarang dalam memberikan pujian dan semangat pada guru. Supervisi dengan pendekatan ini didasarkan asumsi bahwa mengajar terdiri dari beberapa keterampilan teknis dengan standar dan kompetensi yang telah ditetapkan (Sudarsono, 2016).

Kehadiran supervisor dengan keilmuan yang mantap dan kepemimpinan yang handal di era desentralisasi pendidikan ini sangat diharapkan, sebab apa yang terjadi pada tingkat sekolah salah satu penyebabnya karena sulitnya menemukan panutan yang berkualifikasi dan bisa bekerjasama dengan guru. Pengawas merupakan hasil dari didikan dan olahan akademik serta diproses melalui lembaga yang khusus, bukan karena panjangnya masa kerja seseorang atau hanya sekedar diberikan pelatihan singkat (Sudarsono, 2016).

Fungsi supervisi yang lebih personal di sekolah sangat dibutuhkan, kemampuan supervisor antara lain yaitu memiliki pengetahuan yang profesional, artinya supervisor memang memiliki ilmu kepengawasan, kemampuan mendelegasikan beban tugas secara produktif, kemampuan memahami masalah profesional guru, serta kemampuan supervisor 
dalam menyelenggarakan situasi relasi kerja yang baik antara karyawan, guru dan orang tua (Sudarsono, 2016).

\section{Program Bimbingan Konseling pada tingkat pendidikan (30 SMP yang ada di Provinsi Bengkulu)}

Hasil analisis data mengemukakan bahwa program BK yang dilakukan pada tingkat pendidikan SMP yang ada di provisi Bengkulu termasuk dalam kategori baik dalam pelaksaannya.

Berdasarkan Hasil perhitungan pada tabel 3 dapat diketahui bahwa sebannyak 6 sekolah dengan persentase $20 \%$ dalam kategori sangat baik, 13 sekolah dengan persentase 43,3\% dengan kategori baik, 7 sekolah dengan persentase 23,3\% dalam kategori kurang baik dan 4 sekolah dengan persentase 13,3\% kategori tidak baik. Sehingga dapat dikatakan bahwa program BK yang dilakukan pada tingkat pendidikan SMP yang ada di dalam provinsi Bengkulu dalam kategori Baik, terlihat pada grafik 2.

Dari hasil distribusi frekuensi responden secara keseluruhan Program BK yang di laksanakan di sekolah yaitu lebih dominan kepada layaann dasar berada pada $51 \%$ menjawab selalu dilaksanakan oleh guru BK di sekolah, $42 \%$ pada layanan perencanaan individual, $41 \%$ layanan responsif, dan 21,7\% dukungan sistem. Dari berbagai idikator komponen layanan di dalam angket atau kuesioner yang telah di isi responden, diketahui bahwa layana dasar yang lebih banyak dilaksanakan oleh guru BK dalam menjalankan program BK di sekolah dengan persetase $51 \%$.

Tabel 3

Kategori Program BK di Sekolah (Y)

\begin{tabular}{lllll}
\hline No & Rentang Skor & F & $\boldsymbol{\%}$ & Kategori \\
\hline 1 & $\geq 50$ & 6 & 20 & Sangat Baik \\
\hline 2 & $45-49$ & 13 & 43,3 & Baik \\
\hline 3 & $39-44$ & 7 & 23,3 & Kurang Baik \\
\hline 4 & $\leq 38$ & 4 & 13,3 & Tidak Baik \\
\hline Jumlah & 30 & 100 & \\
\hline
\end{tabular}




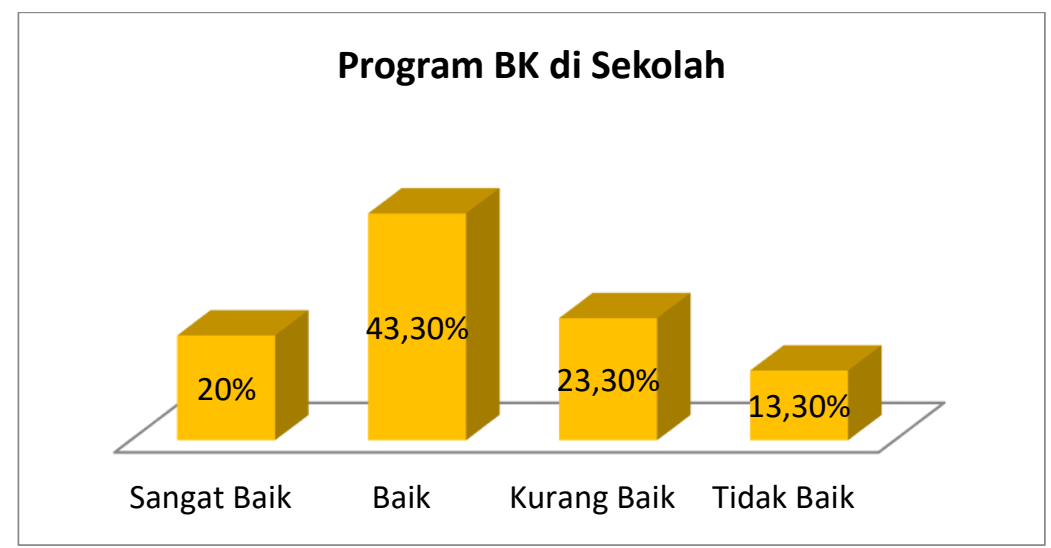

Grafik 2. Program BK di Sekolah

Sehingga dilihat dari hasil yang diperoleh bahwa program BK secara keseluruhan yang dilaksanakan di sekolah dalam satuan pendidikan SMP pada provinsi Bengkulu dalam kategori baik, hal ini berhubungan dengan nilai persentase komponen layanan yang hampir seimbang yang artinya program BK disekolah berjalan denngan baik

Penyusunan rancangan program bimbingan dan konseling sangat memiliki peran penting dalam keberhasilan pelaksanaan layanan bimbingan dan konseling di sekolah. Penyusunan program bimbingan dan konseling disekolah hendaknya disusun berdasarkan permasalahan yang dihadapi oleh peserta didik serta kebutuhan-kebutuhan yang dihadapinya, sehingga akhirnya peserta didik dapat mencapai tujuan pendidikan itu sendiri yaitu kedewasaan dalam bertindak dan berperilaku secara wajar sesuai dengan perkembangan mereka (Fatchurahman, 2017).

Selain itu guru pembimbing juga perlu menjalin kerja sama dengan seluruh personel terkait agar tercipta lingkungan dan budaya pembelajaran yang mengalir akademik karena siswa akan dihadapkn pada tugas-tugas yag memiliki tujuan yang jelas sehingga memerlukan tanggapan khusus dari idividu diluar siswa (Hartini, 2018).

\section{Pengaruh Supervisi Bimbingan Konseling terhadap Efektivitas Pelaksanaan Program BK di Sekolah pada tingkat pendidikan (30 SMP yang ada di Provinsi Bengkulu)}

Berdasarkan tabel 4 hasil uji regersi linier sederhana diatas diperoleh nilai t hitung sebesar 10,68 dan taraf signifikansi sebesar 0,101. Sedangkan untuk $\mathrm{t}$ tabel dengan tarf signifikansi $5 \%(0,05)$ serta df-1 diperoleh nilai $t$ tabel 1,699. Sehingga $t$ hitung $\leq \mathrm{t}$ tabel yaitu $1,696 \leq 1,699$ dan taraf signifikansi $\geq 0,05$ yaitu $0,101 \geq 0,05$. 


\section{Tabel 4}

Hasil Uji Regersi Linier Sederhana

\begin{tabular}{|c|c|c|c|c|c|c|c|}
\hline \multicolumn{8}{|c|}{ Coefficients ${ }^{a}$} \\
\hline \multirow[b]{2}{*}{ Model } & \multicolumn{2}{|c|}{$\begin{array}{l}\text { Unstandardized } \\
\text { Coefficients }\end{array}$} & \multirow{2}{*}{$\begin{array}{l}\text { Standardized } \\
\text { Coefficients } \\
\text { Beta }\end{array}$} & \multirow[b]{2}{*}{$\mathrm{t}$} & \multirow[b]{2}{*}{ Sig. } & \multicolumn{2}{|c|}{$\begin{array}{l}\text { Collinearity } \\
\text { Statistics }\end{array}$} \\
\hline & B & $\begin{array}{l}\text { Std. } \\
\text { Error }\end{array}$ & & & & Tolerance & VIF \\
\hline 1 (Constant) & 39,018 & 3,651 & & 10,686 & ,000 & & \\
\hline SUPERVISI & ,220 & ,130 &, 305 & 1,696 & ,101 & 1,000 & 1,000 \\
\hline
\end{tabular}

Maka sebagaimana dasar pengambilan keputusan dalam uji regresi linier sederhana sebagai berikut:

a. Jika nilai Sig. $\leq 0,05$ mengandung arti bahwa ada pengaruh supervisi BK terhadap efektivitas program BK di sekolah, dan sebaliknya.

b. Jika t hitung $\geq$ dari $t$ tabel maka terdapat pengaruh supervisi $B K$ terhadap efektivitas program BK di sekolah, dan sebaliknya.

Sehingga dapat disimpulkan bahwa H0 diterima dan Ha ditolak yang artinya tidak terdapat pengaruh yang signifikan supervisi BK terhadap efektivitas pelaksanaan program BK di sekolah.

Tidak adanya pengaruh bukan semata-mata supervisi tidak penting bagi efektifitas pelaksanaan program BK, tidak adanya pengaruh disesabkan karena supervisi yang dilakukan di sekolah dalam satuan pendidikan SMP pada provinsi Bengkulu Kurang baik, hal ini berhubungan dengan pendekatan yang banyak dipakai oleh supervisor yaitu pendekatan direktif.

Kehadiran supervisor dengan keilmuan yang profesional serta kepemimpinan yang handal di era desentralisasi pendidikan ini sangat diharapkan, sebab yang terjadi pada tingkat sekolah salah satu penyebabnya karena jarangnya menemukan panutan yang berkualifikasi dan bisa bekerjasama dengan guru. Seorang supervisor seharusnya merupakan hasil dari didikan dan olahan akademik serta diproses melalui lembaga yang khusus, bukan karena panjangnya masa kerja seseorang atau hanya sekedar diberikan pelatihan singkat (Sudarsono, 2016).

Perubahan paradigma supervisor yang dititikberatkan pada HELP memberikan pemahaman bahwa platform pelaksanaan kepengawasan tidak bisa dilakukan secara menyeluruh yaitu one size fit for all, merupakan layanan sama terhadap sekolah dan warga sekolah yang berbeda. Tugas supervisor seringkali terhambat karena ketidaksesuaian 
kemampuan pengawas dengan domaian tugas sekolah. Selama ini asumsi pelaksanaan kepengawasan adalah bahwa sekolah dan siswa serta guru dianggap berkemampuan rerata, padahal sekolah dan guru secara alami bersifat heterogin. Mestinya penyelenggaraan kepengawasan di sekolah dijalankan dengan mengacu self organization by individuals working with the support and advisory systems provided by professionals (Sudarsono, 2016).

Sehingga seorang supervisor harus memiliki salah satu kompetensi supervisor yaitu bisa mengetahui prototipe guru sehingga bisa melakukan supervisi dengan berbagai pendekatan, baik pendekatan langsung, tak langsung, maupun kolaboratif sesuai dengan keragaman problem atau masalah, yang demikian maka desentralisasi dan diferensiasi lebih ditonjolkan sebagai tugas pengawas bukan mementingkan keterlaksanaan tupoksi yang sentralistik.

\section{KESIMPULAN}

Penelitian ini menghasilkan jawaban atau suatu hipotesis yang menyatakan bahwa tidak ada pengaruh yang signifikan antara supervisi BK terhadap efektifitas program BK di sekolah. Hal ini terjadi karena supervisi yang dilakukan di sekolah dalam satuan pendidikan SMP pada provinsi Bengkulu Kurang baik dengan persentase $40 \%$ dan pendekatan yang banyak banyak digunakan yaitu pedekatan direktif dengan persentase 53,3\% sering dilakukan.

\section{DAFTAR RUJUKAN}

Afrijawidiya. (2017). Supervisi Pengajaran Dengan Pendekatan Direktif, Non-Direktif, Dan Kolaboratif. Jurnal Manajer Pendidikan, 11(4), 325-335.

Sudijono, A. (2015). Pengantar statistik Pendidikan. Jakarta: Rajawali Pers.

Azwar, B., Syahindra, W., Widyastuti, R. (2020). Evaluasi Praktik Pengalaman Lapangan Terhadap Dampak Penyeesaian Skripsi Mahasiswa IAIN Curup. TADBIR, 4(2), 216237.

Suwidagdho, D., Lestari, L., \& Dewi, S.P. (2017). Peran Pengawas Bk Untuk Meningkatkan Profesionalitas Guru Bimbingan Dan Konseling. Jurnal Prosiding Seminar Bimbingan Dan Konseling, 1(1), 137-143.

Fatchurahman. (2017). Konsep Dasar Evaluasi Progra Bimbingan Dan Konseling, Tanggerang: Lembaga Literasi Dayak.

Giyono. (2015). Bimbingan Dan Konselin. Yogyakarta: Media Akademi.

Hartini \& Fadila. (2015). Analisis Kebutuhan Mahasiswa Jurusan Tarbiyah Terhadap Pelayanan Konseling. Jurnal Prosiding, 1(1), 190-198.

Hartini. (2018). Budaya Belajar Suku Rejang. JOMSIGN, 2(1), 22-36. 
Kusen. (2016). Pengembangan Perangkat Pembelajaran Kontekstual Pada Pendidikan Agama Islam di SMP Negeri 1 Curup Kabupaten Rejang Lebong. Jurnal el-Hekam, $1(1), 107-116$.

Kurniawan, L. (2015). Pengembangan Program Layanan Bimbingan Dan Koseling Komprehensif Di SMA. Jurnal Psikologi Pendidikan Dan Konseling, 1(1), 1-8.

Amelisa, M \& Suhono. (2018). Supervisi Bimbingan Konseling Dalam Meningkatkan Peguasaan Keterampilan Layanan Konseling Guru BK. Jurnal Tapis, 2(1), 109-127.

Mufidah, L. N. (2008). Supervisi Pendidikan. Jember: Center For Society Studies.

Sudarsono. (2016). Implementasi Pendekatan Direktif, Non Direktif Dan Kolaboratif Dalam Supervisi Di MAN Trenggalek. Jurnal Kabilah, 1(2), 335-358.

Widyowati, T. (2016). Pengaruh Supervisi Kepala Sekolah Terhadap Kinerja Guru Bimbingan Dan Konseling Di Sekolah Menengah Atas (SMA) Negeri Sekabupaten Pati Tahun Ajaran 2014/2015. (Unpublished Thesis), Universitas Negeri Semarang, Semarang, Indonesia. 